\title{
Use of HCI for the development of emotional skills in the treatment of Autism Spectrum Disorder: A systematic review
}

\author{
Gustavo Constain \\ University of Cauca \\ Cauca, Colombia \\ gmr@unicauca.edu.co
}

\author{
Cesar Collazos \\ University of Cauca \\ Cauca, Colombia \\ ccollazo@unicauca.edu.co
}

\author{
Fernando Moreira \\ REMIT, IJP, University \\ Portucalense, Porto \\ IEETA, University of Aveiro, Aveiro \\ Portugal \\ fmoreira@upt.pt
}

\begin{abstract}
This document presents the initial advances found in the literature review that analyzes the relationship between the development of skills inherent to emotional intelligence, and its usefulness in the improvement of treatments for Autistic Spectrum Disorder, through the use of human computer interaction.
\end{abstract}

Keywords - Emotional skills, ASD, HCI, Interaction.

\section{INTRODUCTION}

One of the biggest problems in education is the inadequate management of emotions, this due to lack of training in aspects such as collaborative learning, social adaptation, decision making, the ability to face conflicts, that is, what is known as emotional intelligence [1]. This shows a direct relationship between emotional intelligence and learning, however, the training processes in general focus more on the student's adaptability to certain social processes and group work [2]. This situation becomes more complex when analyzing the process of training and treatment of people with some type of disability, especially the Autism Spectrum Disorder -ASD.

In the case of people with ASD, the pace of work of each person, their abilities and needs will vary depending on their characteristics and their progress, which makes it necessary to carry out digital applications easily adaptable to these needs [3]. Therefore, new alternatives for the use of computational tools, based on human computer interaction (HCI), should be deepened in order to improve the emotional and social conditions of children with ASD that lead to the improvement of their quality of life. In this regard, the research proposal that gave rise to this article has as its fundamental purpose the development of emotional intelligence skills in children with ASD, through the design with principles of interaction and accessibility, of a technological resource linked to processes of autism treatment. Therefore, the research process begins with a systematic review that evidences the state of the art and the technique on the use of computational applications for the treatment of ASD.

\section{METHODOLOGY}

As it is an exploratory investigation of a mixed nature, we opt for a systematic review for the collection of information of interest in the topics considered important.

This methodology has been selected because it has all the necessary elements to carry out the search for information on the proposed topic. The importance of the mapping of the systematic review is found in the structure and steps it proposes to carry out the searches in an organized and methodological way, which helps to generate reliable results in the research (Fig. 1) [4].

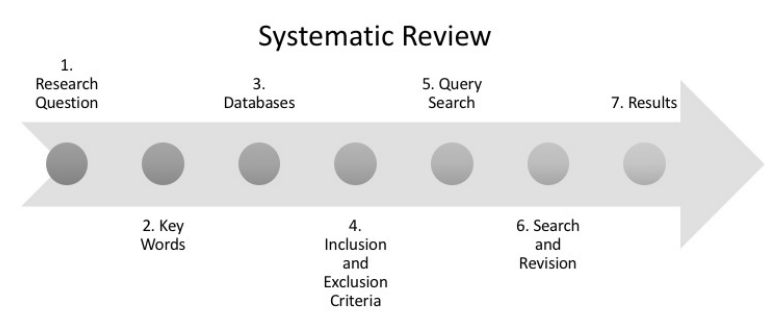

Figure 1. Process for systematic review.

A. Research questions

RQ1: What current treatments have been more accepted and used by the international therapeutic community for the treatment of Autism Spectrum Disorder?

RQ2: What models of computational applications and especially HCI have been used for the treatment of Autism Spectrum Disorder?

RQ3: How does the use of HCI facilitate the design of computational applications that improve the current treatments of Autism Spectrum Disorder?

\section{B. Basic Definitions}

To have greater clarity in the terms used in the document, a definition of the concepts table was made (Table 1). The concepts are related to the search queries used in the systematic review. 
TABLE I.

CONCEPTS DEFINTION

\begin{tabular}{|c|l|}
\hline Word & \multicolumn{1}{|c|}{ Definition } \\
\hline \multirow{3}{*}{ ASD } & $\begin{array}{l}\text { Autism Spectrum Disorder. Is part of permanent } \\
\text { neurological development disorders, in which the areas } \\
\text { related to social interaction, communication, behavior, } \\
\text { interests, and others are deteriorated. }\end{array}$ \\
\hline Model & $\begin{array}{l}\text { Graphic or verbal representation or simplified version of } \\
\text { a concept, phenomenon, relationship, structure, system } \\
\text { or an aspect of the real world. A representation of a } \\
\text { system that allows the investigation of the properties of } \\
\text { the system and, in some cases, the prediction of future } \\
\text { results. }\end{array}$ \\
\hline HCI & $\begin{array}{l}\text { Human-Computer Interaction. Is a discipline related to } \\
\text { the design, evaluation, development and study of the } \\
\text { phenomena surrounding computer systems for human } \\
\text { use. }\end{array}$ \\
\hline Architecture & $\begin{array}{l}\text { It is a level of design that focuses on structural aspects } \\
\text { of software applications such as the global control } \\
\text { structure and general organization; communication } \\
\text { protocols, synchronization and data access; assignment } \\
\text { of functions to design elements; physical distribution, } \\
\text { composition of design elements; fit and performance. }\end{array}$ \\
\hline Emotional & $\begin{array}{l}\text { It is the ability to identify, understand and manage } \\
\text { emotions correctly, in a way that facilitates relationships } \\
\text { with others, the achievement of goals and objectives, the } \\
\text { management of stress or overcoming obstacles. }\end{array}$ \\
\hline \multirow{2}{*}{ Intelligence } & \\
\hline
\end{tabular}

\section{Key Words}

For the systematic review, the search for the key words in English and Spanish (Table II) was defined to include greater results of the searches and to allow a more complete revision in the databases.

TABLE II. KEY WORDS FOR CONSULTATIONS

\begin{tabular}{|c|c|}
\hline Spanish & English \\
\hline Habilidades & Abilities \\
\hline Autismo & Autism \\
\hline Tratamiento & Treatment \\
\hline Emociones & Emotions \\
\hline Modelo & Model \\
\hline Arquitectura & Architecture \\
\hline
\end{tabular}

\section{Data Bases}

For the development of the research five databases (Table III) were defined to perform the information search according to the systematic review. They were chosen because they are the most internationally recognized in the area of engineering, informatics and education, in addition to having good indicators for the publication of articles, conferences, book chapters and others.

TABLE III. DATA BASES CONSUlTED

\begin{tabular}{|c|c|c|}
\hline BD Name & Link & Acronym \\
\hline Google Scholar & https://scholar.google.com & GS \\
\hline SCOPUS & www.scopus.com & SCOPUS \\
\hline Web of Science & https://webofknowledge.com & WOS \\
\hline IEEE Xplore & $\begin{array}{l}\text { http://ieeexplore.ieee.org/Xplore/home } \\
\text {.jsp }\end{array}$ & IEEE Xplore \\
\hline Science Direct & www.sciencedirect.com & $\begin{array}{c}\text { Science } \\
\text { Direct }\end{array}$ \\
\hline
\end{tabular}

\section{E. Inclusion and exclusion criteria}

The inclusion and exclusion criteria of the systematic review were defined according to the topics found in the project and the research questions for the searches.

The inclusion criteria are:

- $\quad$ Articles published between the years 2013-2018;

- Articles published in congresses, journals and book chapters;

- Articles written in English or Spanish;

- Articles found in the databases detailed in Table 2, and

- Articles related to emotional skills, autism spectrum disorder, interaction and human-computer interaction.

The exclusion criteria are:

- Document not available for download;

- Articles in languages other than English and Spanish;

- Articles that do not focus on the use of computational applications for the treatment of autism, and

- Gray literature.

Once the basic inclusion and exclusion criteria have been applied, the titles and the summary of each work are reviewed. With this initial review, it is decided if the article is initially included in the accepted articles. After this process, each article is reviewed in a general way to know if it helps to answer the questions posed in the systematic review.

\section{F. Search strings}

A general search query was defined based on the general concepts of the search title and which allowed answering the research questions posed. For each of the databases, we reviewed how to perform advanced searches and defined the search query for each of them, allowing more specific results according to the key words.

The result of the general search string is as follows:

(("methodolog*" OR "methodological") OR ("model*")) AND ("treatment") AND ("autism*" OR "ASD" OR "syndrome")

\section{G. Search process}

A general search query was defined based on the general concepts of the search title and which would allow answering the research questions posed. For each of the databases, we reviewed how to perform advanced searches in each database and defined the search chain for each of them, allowing more specific results according to the key words.

Once all the information of the searches in the databases was unified in a spreadsheet, 542 items were found in the databases and with them the review process is initiated. In the first place, a general review is carried out to find the articles, book chapters, etc., 75 articles were repeated, originated by the different searches in the databases and by different search queries. 
Then, a revision of the titles and the summary of the works was carried out. This review took into account the inclusion and exclusion criteria, all the information relevant to the planned search and that will help answer the questions initially raised. The general summary of the accepted works is detailed in Fig. 2.

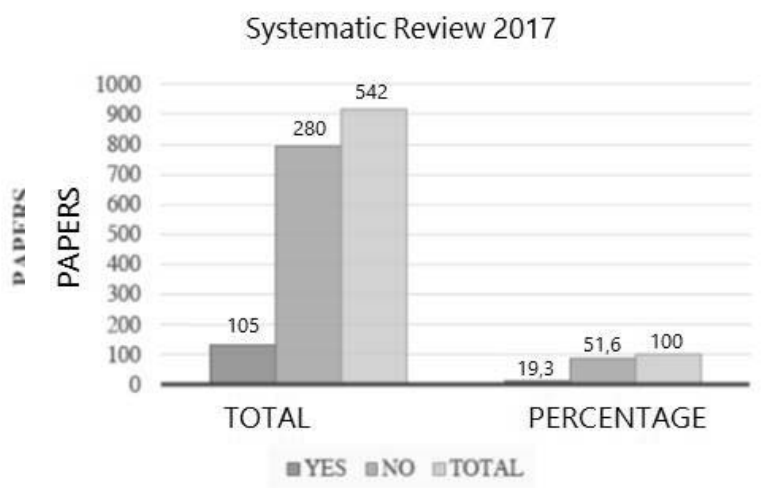

Figure 2. Papers accepted in the systematic review

\section{PARTIAL RESULTS FOUND}

\section{A. Related to autistic spectrum disorder}

Autism Spectrum Disorder (ASD) is part of permanent neurological development disorders, in which the areas related to social interaction, communication, behavior, interests and others are deteriorated [12].

According to [6] in the educational environment importance is given to the affective dimension of learning processes. However, this author explains that the emotional aspects in education continue to be a complex challenge in our present.

Similarly, [7] explains that emotion is composed of three components: Neurophysiological, Behavioral and Cognitive. The neurophysiological component is manifested in aspects such as breathing, sweating and hypertension, which although they are involuntary responses that the individual cannot control, clarifies that if they can be prevented by appropriate techniques. The behavioral component is related to facial expressions, nonverbal language, and tone of voice and body movements, among others. Unlike the neurophysiological component, these expressions are controllable and provide fairly accurate signals about the emotional state of the person. The cognitive component is the one that is related to the feelings, because fear, anguish and anger, among other emotions are expressed in this component.

The author distinguishes the cognitive component of the neurophysiological, in terms of emotion and feeling. That is, the body state (neurophysiological) expresses emotion and is a sensation that occurs unconsciously, while the mental state (cognitive) expresses the feeling and does so consciously.

If we transfer the components proposed by [7] to a scenario where the learner is a person with particular characteristics of physical and cognitive development, such as a child with ASD, the identification and work scenario of the neurophysiological, behavioral and cognitive aspects in a more complex way and requires a more detailed understanding of its nature and particular conditions.

The diversity of hypotheses about the nature of the autistic disorder that has occurred during the last decades, all of them focused more on the cause than on the underlying mental processes, has greatly limited the efficacy of the different treatments applied for their "rehabilitation" [8].

Fortunately, in recent years, the advances made in research on the mental and cognitive aspects of people with ASD, together with personal communications made by many of these people about how they saw and see the world around them, have allowed get closer to their minds [8]. The above allows to have a more accurate idea of how a child with ASD sees the world around him, and what are the difficulties that appear in his relationship with him.

Particularly, one of the aspects of greatest difficulty in the development of the state of the art related to this project, has been to discover the diversity of manifestations that the autistic disorder presents. This diversity is reflected in terms of the chronological age of the person, their mental age and the level of severity of the disorder presented, finding as a first element that each case of autism identified is completely different from the others, that is, that it does not a treatment could be generalized for several cases of autism diagnosed but a specific one should be designed for the case studies that are selected for the experimental phase of the investigation. This circumstance has been sometimes so disconcerting that the previous experience of dealing with a person with ASD, without the accompaniment of a non-specialized professional, in some cases has prevented the recognition of this disorder in another person.

Some particularities [8] of people with ASD are used to identify the characteristics that must be taken into account for the design of computational solutions that contribute to the treatments currently used. Among these characteristics we have:

- Visual thinking;

- Difficulty in anticipation;

- Sensory alterations;

- Difficulties in central coherence (To find differences between objects or people);

- Executive functions (impulse control).

The use of technologies to improve and particularly stimulate the communication of children with ASD has recently increased exponentially. These tools in therapeutic contexts make possible a generalization of behavior towards the child's natural contexts. Therefore, the use of personalized software in mobile devices will allow you to advance with your treatment outside the clinical scope and can use it in your home/school to communicate with your close social links and this can help the use of human-computer interaction models (HCI).

\section{B. Development of emotional and social skills in children with $A S D$}

Communication is one of the most important goals in the work process of a person with autism [9], so the development of 
this skill must be present in all situations of their treatment. We must take advantage of any situation to promote communication, whether in a work or leisure context. The important thing is to create multiple situations to encourage the person to communicate, attending at all times to their acts and communicative reactions.

According to [10] "All autistic subjects have, to a greater or lesser degree, a failure to adequately develop communication and linguistic skills." Language disorders can vary, "ranging from total absence of speech to simply delayed acquisition. That is accompanied by features deviated from the language."

Every communicative act consists of several components:

TABLE IV. COMPONENTS OF THE COMMUNICATIVE ACT

\begin{tabular}{|l|c|c|c|}
\hline \multicolumn{1}{|c|}{ Modality } & Function & Content & Context \\
\hline Nonverbal: & Petition & & \\
Instrumental acts & Rejection & Object & Place \\
Natural gestures & Answer & Action & Person \\
Alternative & Question & Person & \\
Communication & Commentary & & \\
Systems (ACS) & & \\
\hline
\end{tabular}

According to the components presented in Table IV, the behavior of the child with ASD is analyzed and according to the results the particular comprehensive educational intervention program is elaborated. It must be taken into account that a person with ASD usually manifests deep and complex alterations in the area of communication, both verbal and non-verbal, presenting absence of communicative intention and / or alterations in the use of language [10]. Therefore, within non-verbal communication, we must distinguish between instrumental acts, natural gestures and SAC (alternative communication systems).

The treatment programs that are expected to work within the research will focus mainly on alternative communication systems that are designed by computer applications under the approach of accessibility and human computer interaction.

\section{Current treatment and education programs}

The TEACCH program ("Treatment and Education of Autistic and Related Communication Handicapped Children") provides different services for people with autism and associated disorders, as well as for their families [11]. Its founder, Eric Schopler, has developed, through numerous publications in "The TEACCH Division", various programming and a methodology of enormous influence in working with people with serious communication difficulties and therefore applicable to students who are they are framed within the autistic spectrum [10] [11].

The use of TEACCH as a treatment model (Fig. 3) seeks to achieve that through the application of the prepared activities, the child with ASD achieves an improvement in their autonomy, while avoiding the difficulties of communication and understanding of language [12]. The tasks for children with ASD who begin to work on this methodology are those tasks that are manipulative and that teach the principles of the task: the idea of complement, of looking for instructions, use of materials and everything that is defined for the emotional or social competences that you want to work.
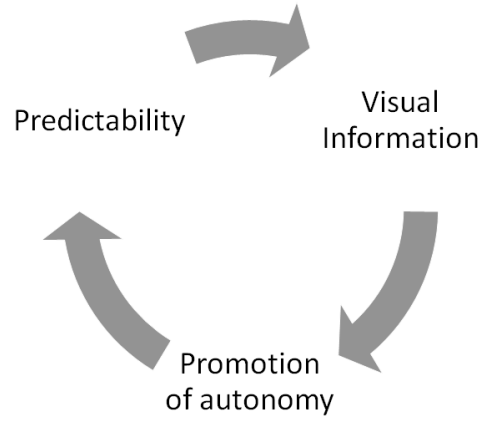

Figure 3. TEACCH Model.

It is noteworthy that those who work with people with autism should know that motivation is key to learning. Attention and motivation increase when activities are clearly designed. Any activity that you want to do, you have to design it as if it were an activity with TEACCH characteristics.

An alternative to TEACH has been the use of software applications with NFC technology ("Near Field Communication") for children with functional diversity that, through their use on mobile devices, use animated pictograms to represent everyday activities of a person, with which seeks to promote communication, allow planning, organize and anticipate certain activities.

It is expected that these tools contribute to conventional therapies and favor a better social interaction. The activities of the applications are designed to be developed in a tripartite manner, that is, the interaction between the child, new technologies and the professional or tutor will be encouraged and is aimed at being transferable to different reference areas of the child, mainly the family and school [26].

Some other identified experiences, as in the case of [27] have experimented with animal-assisted therapies (AAT) which is defined as "an intervention designed to improve the cognitive, physical, social and emotional functioning of a patient, with objectives specific and delimited in time". In the application of the different AAT, different types of animals are used, such as: equines, dolphins, dogs, cats, rabbits, birds, fish, among others. In the cases studied, it is found that the child with ASD soon after becoming familiar with the animal begins to imitate their behaviors.

Although the latest programs presented are innovative, they have started from the TEACCH model to formulate new ways to intervene in cases of experienced ASD.

\section{Computational models to support the treatment of ASD}

Children with ASD, as well as other children who do not suffer from this disorder, have an affinity for ICT information and communication technologies [13]. Taking into account this characteristic, within the treatment of ASD, the use of Natural User Interfaces should be considered, where the user interacts without using command controls or input devices such as the mouse, keyboard, touchpad, joystick, and others [14] [15]. Instead of these controls, gestural movements such as hands or body are used, which become the command control of the 
application. Augmented reality is another concept that has been useful in some cases for the treatment of ASD, used to define a vision through a technological device of a physical environment of the real world, whose elements are combined with virtual elements for the creation of a mixed reality in real time [16].

In the school environment there are children with special educational needs, within these are students with ASD, with characteristics to take into account to carry out a successful and efficient intervention. Since in the school an important part of the life of the children is developed; to favor the personal and social development of these people, it is necessary that the psychoeducational intervention offers answers to individual needs, providing the necessary support in academic instruction and also favoring the integration in their peer group [17].

Regarding the use of applications of this type in the treatment of cases of ASD, it is found that there is no general intervention methodology for an objective evaluation with respect to the level of ease of use of the applications with which it has been experienced, and these must be adjusted in a particular way for each selected case of study. This means that conclusive results must be collected by running tests that evaluate usability in each case.

The above is consistent with the experiences obtained by [17] [18] and [19], who evaluate the usability of the natural user interface through tests conducted through touchless interactions oriented towards the most common actions in children with ASD. Such as clicking, dragging, moving or zooming a series of images (pictograms) on the screen. The usability level is defined by a rating scale divided into a grade of ten where the score of 9 (nine) represents the intuitive experience and no requirement for learning and the score of 0 (zero) represents the worst experience when the interactions do not they are usable at all [17].

For the purposes of our research, it is important to know the results found in other experiences where it is of great value to obtain a set of guidelines applicable to the development of digital applications for people with ASD, where the context of use of the applications made through digital games based on the manipulation of pictograms with the possibility of being printed so that they can be used as learning chips in real environments.

\section{E. Alternatives of application design proposed for support from usability engineering}

The use of computational technologies as a complement to the clinical treatment of ASD intervention brings advantages such as learning at a particular rhythm, the increase in focused attention, and behavioral changes due to the affinity of children to the development of social interactions based on digital interfaces. Facing the same process done face to face in real life.

It is proposed that this computational component be developed under the Usability and Accessibility Engineering Process Model - MPIu+a (Fig. 4), which seeks to cover the aspects related to the Design of User-Centric Interactive Systems (DCU) contemplating all its phases of completion: Analysis, Design, Implementation, Launch, Prototyping and Evaluation [20].

Initially, the development of the model of inclusive computer applications is framed from the concepts related to the disability linked to the ASD and specifically in the development of intrapersonal skills (motivation) and interpersonal skills (social skills) related to emotional intelligence [21]. This has to do with the conceptual organization of the project within the aspects of Software Engineering with the basic principles of Usability Engineering and Accessibility, providing a methodology that is able to guide the development teams during the process of implementation of a specific interactive and inclusive system.

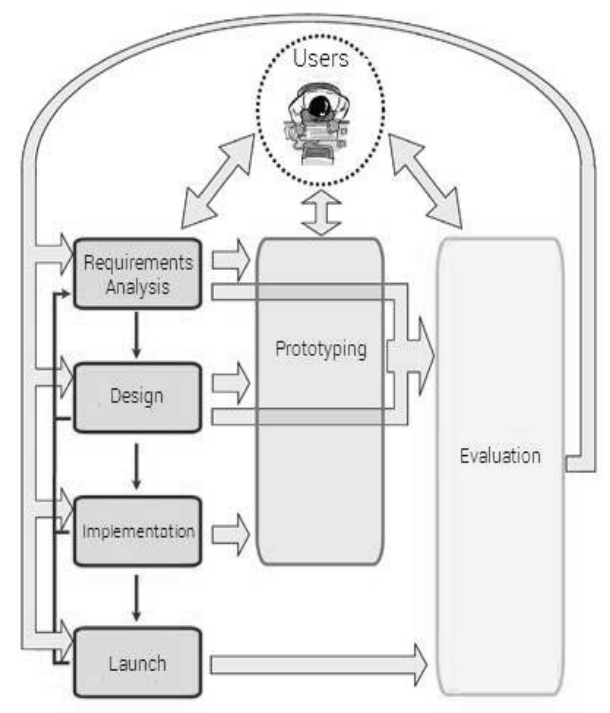

Figure 4. MPIu+a Design Model.

Thinking about the final user of the project, it is intended that usability is a determining factor for inclusive applications that are carried out under this approach, so that the interfaces, communicative capacity and functional structure of the software developed, have to be as simple as possible. Therefore, for the design of the technological model that defines appropriate software architectures, the ISO / IEC 25010 standard must be taken into account.

The application of this model is linked to the design of processes centered on the user and the evaluation of usability in each step carried out, which guarantees that both functional and non-functional requirements are met from the beginning of the design of the applications and not until the end that the tests are carried out.

\section{CONCLUSIONS AND FUTURE WORK}

The documents that were selected in the first part of the state of the art made, allow to discover the current treatments have been more accepted and used by the international therapeutic community at present for the treatment of Autism Spectrum Disorder [2] [8] [9]. Accordingly, the TEACCH model is a didactic center for the formulation of new therapeutic initiatives and has originated programs such as the use of mobile devices with NFC technology or even the use of animals. Notwithstanding the above, no research or projects have been found related to the combined application of the above elements, that is, the use of software tools that use NFC technology for the 
presentation of animated pictograms of animals, in addition to the inclusion of elements of serious games that support the current treatment of children with ASD or even with other functional diversity, so it would be a contribution to new practices of inclusive education in this area of knowledge.

With respect to the model for the design of computational applications that support the treatments of ASD, although in the selected literature there is the use of applications within some treatments with important results for the improvement of the behavior of children with ASD [3] [13], it is evident that it is not possible to generalize a treatment for various cases of autism that have been diagnosed, therefore, a specific treatment must be designed for each case and in this sense it will also have to make specific adjustments to the computational application that is designed from the focus of the principles of interaction and accessibility [11]

Consequently, it is found that the design of computer application interfaces that support the treatment of ASD should be based on the use of their own models, such as the MPIU+ and integrate it into serious games models, for the development of customized solutions, appropriate in each particular case [20] [21].

Taking into account the characteristics of children with ASD and their affinity with the management of pictograms in computational applications, a new systematic review will add the query about computational applications that build stories (sequence of images through their use in mobile devices), where the analysis of the functionalities, emotional skills and the necessary tasks that the child intends to obtain, as well as a modeling at a conceptual level, looking for an approximation to the real life of these people, this proved in a basic way in the investigation [12].

Finally, it must be taken into account that the design of computational applications to support the treatment of children with ASD should include the design of adequate interfaces (preferably non-invasive), functional diversity and guarantee an appropriate play interaction for cases of ASD be analyzed. In this the use of usability models and human-computer interaction would be of great help.

\section{REFERENCES}

[1] R. M. M. González, and N. A. Ibarra. "Inteligencia emocional en educación”. Revista Complutense de Educación, Vol. 27 No. 2, PP. 887888. 2016.

[2] M. G. Calle Marquez, and N. Remolina De Claves, "Incidencia de la inteligencia emocional en el proceso de aprendizaje". NOVA Publicación Científica EN CIENCIAS BIOMÉDICAS, Vol. 112. 2011.

[3] R. Villalta, A. Sánchez Cabaco, J. Villa Estevez, "Diseño de aplicaciones digitales para personas con TEA". International Journal of Development and Educational Psycology. Vol. 4, n. 1, pp. 291-297. 2012.

[4] F. M. M. Petersen, R. Feldt, and S. Mujtaba, "Systematic Mapping Studies in Software Engineering" 2008.

[5] B. Kitchenham and S. Charters, "Guidelines for performing Systematic Literature Reviews in Software Engineering," Engineering, Vol. 2, p.p. 1051, 2007.

[6] L. Nuñez Cubero. "La educación emocional como modelo de intervención para prevenir la violencia de género." Revista Educación, género y políticas de igualdad. XI Congreso Nacional de Teoría de la Educación. p.p. 171-183. 2008.

[7] R. Bisquerra. "Educación emocional y competencias básicas para la vida." Revista de Investigación Educativa, Vol. 21. n. 1, p.p. 7-43. 2013.

[8] S. Repeto Gutierrez. "Naturaleza de los trastornos del espectro autista. Los trastornos generales del desarrollo: una aproximación desde la práctica." Vol. 1. Consejería de la educación. Junta de Andalucía. 2010.

[9] A. Molina Montes. "Cómo potenciar la comunicación en el alumnado con trastorno de espectro autista. . Los trastornos generales del desarrollo: una aproximación desde la práctica.” Vol. 1. Consejería de la educación. Junta de Andalucía. 2010.

[10] P. Gortázar. "La respuesta educativa ante las dificultades en el ámbito de la comunicación y el lenguaje." -Intervención educativa en autismo. Jornadas de autismo.- Tenerife. 2001.

[11] Ma. Del C. Martín Rodríguez, "La respuesta TEACCH en el aula para alumnos/as dentro del espectro autista." -Intervención educativa en autismo. Jornadas de autismo.- Tenerife. 2001.

[12] R. Muñoz, S. kreisel. "Proyect@Emociones: Software para Estimular el Desarrollo de la Empatía en Niños y Niñas con Trastornos del Espectro Autista." Conference Paper recuperated of: www.researchgate.net/publication/234166847. 2012.

[13] Jornadas Universitarias de Tecnología Educativa (JUTE 2011) Universidad de Sevilla, España. Las Tecnologías de la Información y Comunicación (TIC) en el Proceso de Enseñanza y Aprendizaje del Alumnado con Trastorno del Espectro Autista (TEA). 2011. http://congreso.us.es/jute2011/es/comunicaciones.php

[14] E. Liddy; W. Paik; M. McKenna. "User interface and other enhancements for natural language information retrieval system and method." 2016

[15] W. Liu. "Natural user interface- next mainstream product user interface." Computer-Aided Industrial Design \& Conceptual Design (CAIDCD), IEEE 11th International Conference. 2011.

[16] S. Cawood, M. Fiala. "Augmented Reality, a practical guide." The Pragmatic Bookshelf. ISBN 978-1-93435-603-6.- 2008

[17] V. Contreras; D. Fernandez. "Interfaces Gestuales para niños que padecen el Trastorno del Espectro Autista." -Dirección de Sistemas y Comunicaciones, Universidad Nacional de José C. Paz, Leandro N. Alem 4731, José C. Paz, Provincia de Buenos Aires, Argentina. 2016.

[18] R. Lara Cruz; H. Fernandez; A. Olvera. "Plataforma interactiva Kinect aplicada al tratamiento de niños autistas." -Informe final de tesis de pregrado en ingeniería de comunicaciones y electrónica. Instituto politécnico Nacional. México D.F. 2013.

[19] M. Renilla; A. Sanchez; J. Estevez. "Diseño de aplicaciones digitales para personas con TEA." -Revistas Científicas de América Latina, el Caribe, España y Portugal. Sistema de Información Científica.- 2012.

[20] T. Granollers. "MPIu+a Una metodología que integra la ingeniería del software, la interacción persona-ordenador y la accesibilidad en el contexto de equipos de desarrollo multidisciplinares.” 2007.

[21] G.E. Constain Moreno. "Model proposal for architecture for inclusive computational applications, in the treatment of autista-spectrum disorder". Unplublished. Universidad del Cauca -Colombia. 2018.

[22] E. Schopler and G. Mesibov. "Behavioral issues in Autism." -Ed. Plenium Press.- 1994.

[23] E. Schopler. and M.E. Van Bourgondien. "Preschool issues in autism." Editorial Plenium. 1993.

[24] E. Schopler and G. Mesibov. "Learning and cognition in autism." Ed.Plenium Press. 1995.

[25] R. Koegel and L. Kern. "Teaching children with autism." 1995.

[26] V. Contreras, M. García, V. Moreno, A. Langer. Aplicaciones de software con tecnología NFC en dispositivos móviles, para niños con diversidad funcional. 2017.

[27] M.D. Jara Gil. Terapia asistida con perros (TAP) aplicada a niños con trastorno del espectro autista (TEA) en edad escolar. Universidad Nueva Granada. 2016 